Effect of molecular weight distribution on e-beam exposure properties of polystyrene

This article has been downloaded from IOPscience. Please scroll down to see the full text article.

2013 Nanotechnology 24245302

(http://iopscience.iop.org/0957-4484/24/24/245302)

View the table of contents for this issue, or go to the journal homepage for more

Download details:

IP Address: 129.97.40.81

The article was downloaded on 10/06/2013 at 22:31

Please note that terms and conditions apply. 


\title{
Effect of molecular weight distribution on e-beam exposure properties of polystyrene
}

\author{
Ripon Kumar Dey and Bo Cui \\ Department of Electrical and Computer Engineering and Waterloo Institute for Nanotechnology (WIN), \\ University of Waterloo, 200 University Avenue West, Waterloo, ON, N2L 3G1, Canada \\ E-mail: bcui@uwaterloo.ca
}

Received 24 January 2013, in final form 25 April 2013

Published 20 May 2013

Online at stacks.iop.org/Nano/24/245302

\begin{abstract}
Polystyrene is a negative electron beam resist whose exposure properties can be tuned simply by using different molecular weights (Mw). Most previous studies have used monodisperse polystyrene with a polydispersity index (PDI) of less than 1.1 in order to avoid any uncertainties. Here we show that despite the fact that polystyrene's sensitivity is inversely proportional to its $\mathrm{Mw}$, no noticeable effect of very broad molecular weight distribution on sensitivity, contrast and achievable resolution is observed. It is thus unnecessary to use the costly monodisperse polystyrene for electron beam lithography. Since the polydispersity is unknown for general purpose polystyrene, we simulated a high PDI polystyrene by mixing in a 1:1 weight ratio two polystyrene samples with Mw of 170 and $900 \mathrm{~kg} \mathrm{~mol}^{-1}$ for the high Mw range, and 2.5 and $13 \mathrm{~kg} \mathrm{~mol}^{-1}$ for the low Mw range. The exposure property of the mixture resembles that of a monodisperse polystyrene with similar number averaged molecular weight $\overline{\mathrm{Mn}}$, which indicates that it is $\overline{\mathrm{Mn}}$ rather than $\overline{\mathrm{Mw}}$ (weight averaged molecular weight) that dominates the exposure properties of polystyrene resist. This also implies that polystyrene of a certain molecular weight can be simulated by a mixture of two polystyrenes having different molecular weights.
\end{abstract}

\section{Introduction}

Despite its low throughput, electron beam lithography (EBL) is still the most popular nanolithography method for research and development, with its performance mainly determined by the resist for a given tool. Positive resist is more popular for EBL because of the availability of the benchmark resist poly(methyl methacrylate) (PMMA), as well as ZEP resist that offers higher sensitivity and etching resistance than PMMA. For some applications such as the fabrication of hole arrays in a film of $\mathrm{Au}$, liftoff is the only option for pattern transfer since Au cannot be etched by reactive ion etching (RIE). Then negative resist would offer substantially shorter exposure time in the liftoff process, except when using a complicated 'resist tone reversal' process [1]. Bilenberg et al have selected four negative EBL resists and compared their performance: calixarene (Tokuyama Corp), ma-N 2401 (Microresist Technology), SU-8 (Microchem Corp) and mr-L 6000 (Microresist Technology) [2]. Hydrogen silsesquioxane (HSQ) is another attractive negative resist used in recent years.
However, none of the above has gained similar popularity to PMMA and ZEP resists because each has its own limit, such as the low resolution for chemically amplified SU-8 and mr-L 6000 resists, the low sensitivity of calixarene and the instability of HSQ [3].

In addition, all the above resists are commercially formulated with typically high cost and short shelf life. Therefore, it is desirable to have a negative resist like PMMA, which is a simple polymer with low cost and practically unlimited shelf life that can be dissolved easily using various solvents to give desired film thickness. Polystyrene is such a resist, as it undergoes cross-linking when exposed to deep UV light or an electron beam. Many solvents that can dissolve the linear polystyrene can be used as its developer, such as acetone, tetrahydrofuran, chlorobenzene, anisole and xylene. Polystyrene is much more resistant to plasma etching than PMMA. In addition, it can be dry thermally developed to reduce pattern collapse due to capillary force when using solvent development [4], and it can also be thermally evaporated for EBL on any (non-flat, non-planar) surface such 
as on an optical fiber [5]. More importantly, its exposure properties such as sensitivity and resolution can be tuned simply by using different molecular weights (Mw). Previously we have demonstrated ultra-high resolution patterning using a low $\mathrm{Mw}$ of $2 \mathrm{~kg} \mathrm{~mol}^{-1}$ [6] and ultra-high sensitivity using a high $\mathrm{Mw}$ of $900 \mathrm{~kg} \mathrm{~mol}^{-1}$ [7]. In addition to molecular weight, another important parameter for a polymer is the polydispersity index (PDI), which is defined as the ratio of weight averaged molecular weight $\overline{\mathrm{Mw}}$ and number averaged molecular weight $\overline{\mathrm{Mn}}$. For a strictly monodisperse polymer, $\overline{\mathrm{Mn}}$ is equal to $\overline{\mathrm{Mw}}$ and the PDI is 1 . For a polymer with broad molecular weight distribution, the PDI is much higher than 1. The PDI is known to be an important parameter for micro-phase separation of a mixture of heterogeneous polymer [8], as well as for crystallization kinetics [9].

In previous studies by us [4-7] and other research groups [10-16], in order to avoid any uncertainties, polystyrene with very narrow molecular weight distribution with PDI $\leq 1.06$ has been utilized. Ku's paper published in 1969 also recommended polystyrene with narrow $\mathrm{Mw}$ distribution for EBL in order to avoid potential pinhole formation after development [17]. In this study we will show that there is no significant effect of very broad molecular weight distribution on resist contrast and achievable resolution. We didn't observe any pinhole formation after development, either. It is thus unnecessary to use monodisperse polystyrene whose cost is more than two orders higher than the general purpose polystyrene having high PDI.

\section{Experimental details}

Polystyrene powder with various molecular weights and polydispersity indices (from Pressure Chemical Co. and Scientific Polymer Products Inc.) was dissolved in chlorobenzene with a concentration of $1-2 \mathrm{w} / \mathrm{v} \%$. The film thickness depends on the polystyrene concentration and spin speed. A relatively thick film is desirable for a contrast curve measured by AFM since the measurement is more accurate for thicker films, whereas a relatively thin film is preferred for high resolution line array exposure because pattern collapse due to capillary force is less severe for thinner films. Before spin-coating, the silicon wafer was cleaned using acetone and 2-propanol, followed by nitrogen drying. The films were baked at $120^{\circ} \mathrm{C}$ for $5 \mathrm{~min}$ on a hotplate for the high $\mathrm{Mw}$ samples (170 kg mol $\mathrm{m}^{-1}$ and above). For low Mw polystyrene resist (13 kg mol ${ }^{-1}$ and below), we decreased the baking temperature to $70^{\circ} \mathrm{C}$ and increased the time to $1 \mathrm{~h}$ in order to obtain a uniform and homogeneous film.

Electron beam lithography was performed using a LEO 1530 field emission SEM that is equipped with Nabity nanometer pattern generation system (NPGS) and a Raith $150^{\text {TWO }}$ tool. The pattern was exposed using the LEO tool at $20 \mathrm{kV}$ with $100 \mathrm{pA}$ beam current (20 $\mu \mathrm{m}$ aperture) for the high Mw polystyrene samples, and using the Raith tool at $20 \mathrm{kV}$ with $340 \mathrm{pA}$ beam current (30 $\mu \mathrm{m}$ aperture) for the low Mw polystyrene resists. After exposure, the samples were developed using tetrahydrofuran (THF) for $3 \mathrm{~min}$ for the high Mw polystyrene (170-900 $\left.\mathrm{kg} \mathrm{mol}^{-1}\right)$, followed by a 2-propanol rinse. This relatively long development time is needed since high $\mathrm{Mw}$ polystyrene is less soluble in the solvent than the low Mw one $\left(2.5-13 \mathrm{~kg} \mathrm{~mol}^{-1}\right)$ that was developed for $40 \mathrm{~s}$.

To investigate the effect of PDI on exposure properties, since the PDI of commercially available general purpose polystyrene (expected to have unimodal $\mathrm{Mw}$ distribution) is unknown, we mixed two monodisperse polystyrenes with very different molecular weights (thus bimodal distribution) to mimic a polystyrene with very broad molecular weight distribution and large PDI. For the high $\mathrm{Mw}$ range, 170 $(\mathrm{PDI}=1.06)$ and $900 \mathrm{~kg} \mathrm{~mol}^{-1}(\mathrm{PDI}=1.10)$ polystyrene solutions having the same concentration were mixed with 1:1 volume ratio, to give a film with $1: 1$ weight ratio after spin-coating. For the low Mw range, 2.5 and $13 \mathrm{~kg} \mathrm{~mol}^{-1}$ (both PDI $=1.06$ ) were mixed the same way.

\section{Results and discussion}

For a positive resist based on chain scission such as PMMA, the dependence of resist sensitivity on molecular weight is rather weak; this is because for PMMA of longer chains, though more exposure is needed to cut it to below $\sim 10 \mathrm{~kg} \mathrm{~mol}^{-1}$ (threshold $\mathrm{Mw}$ for fast dissolution in the developer), longer chains also receive proportionally more electron exposure. For instance, when $\mathrm{Mw}$ is decreased from 2200 to $50 \mathrm{~kg} \mathrm{~mol}^{-1}$, its sensitivity increases only by $26 \%$ for room temperature development, from approximately 500 to $370 \mu \mathrm{C} \mathrm{cm}^{-2}$ [18]. Contrary to positive resist, $\mathrm{Mw}$ is fundamentally critical for chain cross-linking negative resist such as polystyrene whose sensitivity is roughly proportional to its Mw [17]. This is because less cross-linking is needed for longer polystyrene chains to render them insoluble in a solvent developer. As for resist contrast and high resolution capability, though typically a high Mw PMMA of $950 \mathrm{~kg} \mathrm{~mol}^{-1}$ is used for electron beam lithography, actually a $\mathrm{Mw}$ as low as $15 \mathrm{~kg} \mathrm{~mol}^{-1}$ can achieve very high resolution of $15 \mathrm{~nm}$ line-width [19]. There is no obvious relationship between high resolution capability (resist contrast) and resist molecular weight for positive resist. But for a chain cross-linking negative resist such as polystyrene, gel formation theory predicts that resist contrast increases as Mw decreases [20, 21], which is in agreement with our previous studies [6, 7]. Given such an overwhelming significance of $\mathrm{Mw}$ on the exposure properties of polystyrene, we studied the effect of polydispersity index over both high and low Mw ranges.

\subsection{Polystyrene with high Mw}

The contrast curves exposed at $20 \mathrm{keV}$ for $170 \mathrm{~kg} \mathrm{~mol}^{-1}$ polystyrene $(\mathrm{PDI}=1.06), 900 \mathrm{~kg} \mathrm{~mol}^{-1}$ polystyrene $(\mathrm{PDI}=$ 1.10) and the 1:1 mixture of the two are shown in figure 1. As expected, the sensitivity for $900 \mathrm{~kg} \mathrm{~mol}^{-1}$ is much higher than that for $170 \mathrm{~kg} \mathrm{~mol}^{-1}$. The sensitivity for $900 \mathrm{~kg} \mathrm{~mol}^{-1}$ is comparable to typical chemically amplified resists such as SU-8; and that for $170 \mathrm{~kg} \mathrm{~mol}^{-1}$ is close to ZEP-520A resist when using a strong developer [23], which is much higher than when using regular high resolution developer. For the 


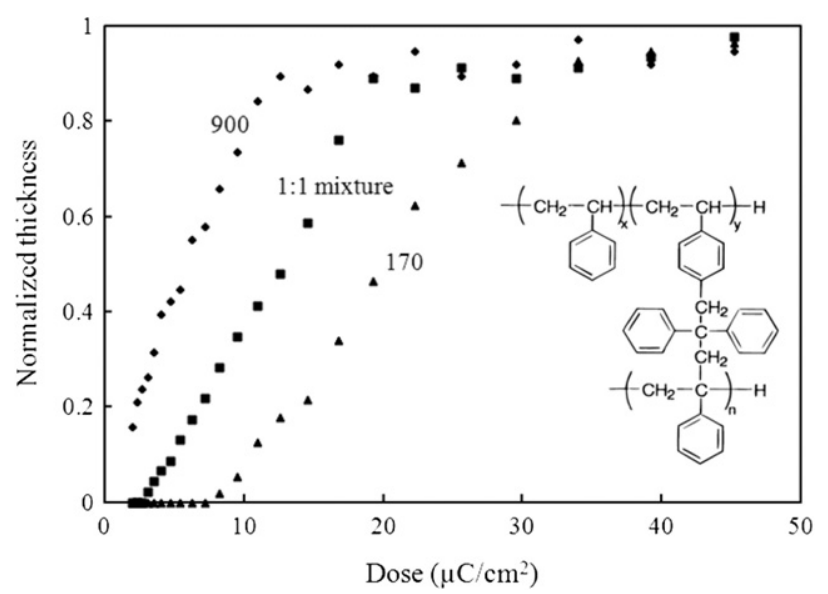

Figure 1. Contrast curves exposed at $20 \mathrm{keV}$ for polystyrene resist of $170,900 \mathrm{~kg} \mathrm{~mol}^{-1}$ and a mixture of the two with $1: 1$ weight ratio. The inset shows a possible configuration of a portion of cross-linked polystyrene. (Adapted from [22], reprinted with permission. Copyright 1997 American Chemical Society.)

mixture with $1: 1$ weight ratio (i.e. $\mathrm{N}_{1} \mathrm{M}_{1}=\mathrm{N}_{2} \mathrm{M}_{2}, \mathrm{M}_{1}=$ $170 \mathrm{~kg} \mathrm{~mol}^{-1}, \mathrm{M}_{2}=900 \mathrm{~kg} \mathrm{~mol}^{-1}$ ), if we assume the two components are strictly monodisperse (i.e. PDI $=1.0$ ), the weight averaged molecular weight can be calculated as $\overline{\mathrm{Mw}}=$ $\left(\mathrm{N}_{1} \mathrm{M}_{12}+\mathrm{N}_{2} \mathrm{M}_{22}\right) /\left(\mathrm{N}_{1} \mathrm{M}_{1}+\mathrm{N}_{2} \mathrm{M}_{2}\right)=(170+900) / 2=$ $535 \mathrm{~kg} \mathrm{~mol}^{-1}$; for a $1: 1$ weight ratio, the number ratio is $\mathrm{N}_{1}: \mathrm{N}_{2}=900: 170$, thus the number averaged molecular weight can be calculated as $\overline{\mathrm{Mn}}=(170 \times 900+900 \times$ 170) $/(170+900)=286 \mathrm{~kg} \mathrm{~mol}^{-1}$. By definition, the polydispersity index of the mixture is $\mathrm{PDI}=535 / 286=$ 1.87. The calculated contrast for the mixture $(\gamma=1.3)$ lies between those of the two components $(\gamma=0.9$ and 1.9 for
900 and $170 \mathrm{~kg} \mathrm{~mol}^{-1}$, respectively). As can be seen from the figure, the contrast curve for the 1:1 mixture resembles a hypothetical monodisperse polystyrene resist with $\mathrm{Mw} \sim$ $300 \mathrm{~kg} \mathrm{~mol}^{-1}$. Therefore polystyrene of certain molecular weight can be simulated by a mixture of two polystyrenes having very different Mw. It is thus unnecessary to have a large number of polystyrene resists with different $\mathrm{Mw}$ for different applications using EBL.

To study the resolution capability of the polystyrene samples, we exposed dense line arrays each over an area of $(5 \mu \mathrm{m})^{2}$ that is larger than the range of electron backscattering for $20 \mathrm{keV}$, so a similar dense array is expected when patterning over larger area. The lines were exposed as single pass lines with step size of $5 \mathrm{~nm}$. As seen in figure 2, the $150 \mathrm{~nm}$ period line array pattern was better defined using the $1: 1$ mixture than $900 \mathrm{~kg} \mathrm{~mol}{ }^{-1}$. The lower $\mathrm{Mw}$ of $170 \mathrm{~kg} \mathrm{~mol}^{-1}$ can well define a line array of $80 \mathrm{~nm}$ period. For comparison, we also studied the resolution capability for a general purpose $260 \mathrm{~kg} \mathrm{~mol}^{-1}$ polystyrene with high polydispersity index (figure $2 \mathrm{~d}$ ), which showed improved pattern definition with smoother lines than the $170 \mathrm{~kg} \mathrm{~mol}^{-1}$ having narrow molecular weight distribution (see below for an explanation). This again manifests that the resist performance greatly depends on molecular weight, but not on its distribution.

\subsection{Polystyrene with low Mw}

The contrast curves exposed at $20 \mathrm{keV}$ for $2.5 \mathrm{~kg} \mathrm{~mol}^{-1}$ polystyrene $(\mathrm{PDI}=1.06), 13 \mathrm{~kg} \mathrm{~mol}^{-1}$ polystyrene $(\mathrm{PDI}=$ 1.06) and the 1:1 mixture of the two are shown in figure 3 . As expected, they all showed considerably higher contrast than
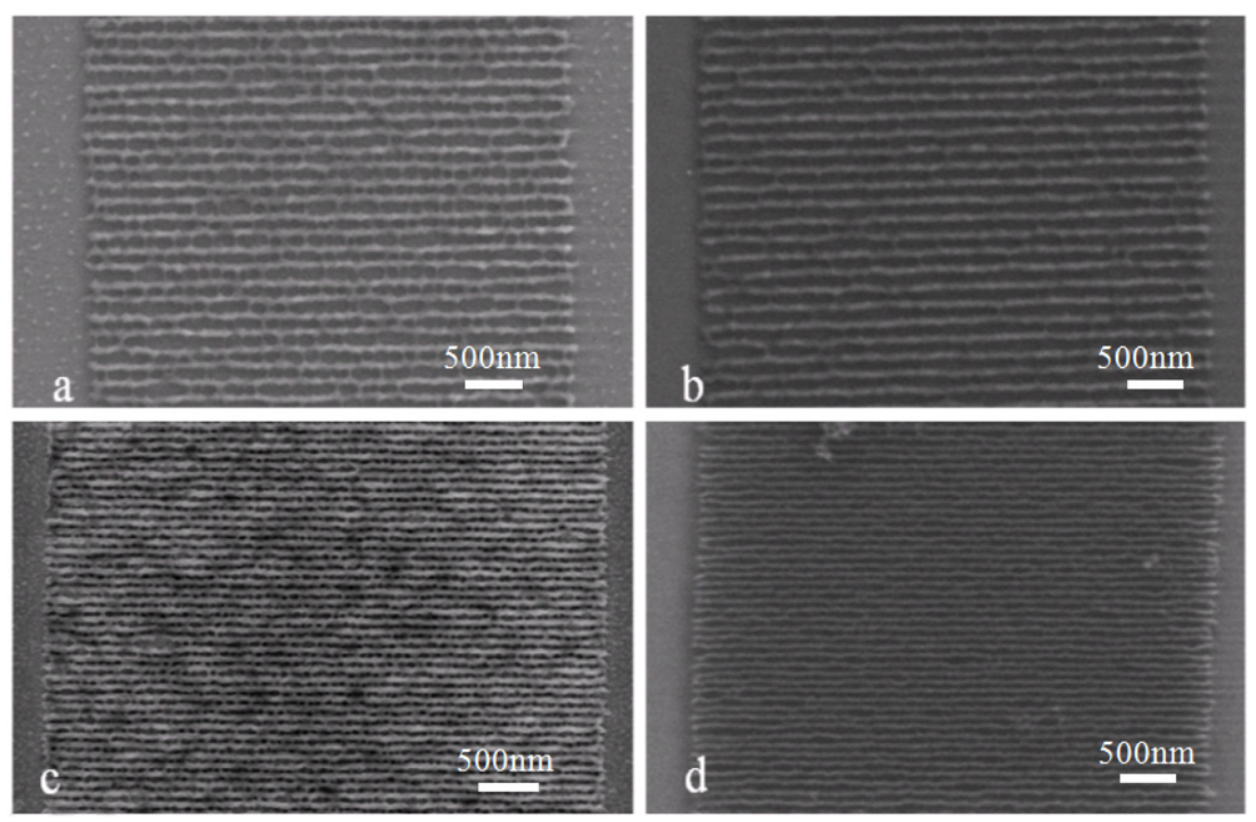

Figure 2. Dense line arrays exposed at $20 \mathrm{keV}$ in polystyrene with different molecular weights: (a) Monodisperse $900 \mathrm{~kg} \mathrm{~mol}^{-1}, 150 \mathrm{~nm}$ period, $0.26 \mathrm{nC} \mathrm{cm}^{-1}$ line dose; (b) $1: 1$ mixture of 170 and $900 \mathrm{~kg} \mathrm{~mol}^{-1}, 150 \mathrm{~nm}$ period, $0.66 \mathrm{nC} \mathrm{cm}^{-1}$; (c) monodisperse $170 \mathrm{~kg} \mathrm{~mol}{ }^{-1}$, $80 \mathrm{~nm}$ period, $1.0 \mathrm{nC} \mathrm{cm}^{-1}$; (d) general purpose polydisperse $260 \mathrm{~kg} \mathrm{~mol}^{-1}, 80 \mathrm{~nm}$ period, $0.91 \mathrm{nC} \mathrm{cm}^{-1}$. 
Table 1. Comparison of exposure properties of the three polystyrene resists, with the values derived from figure 3 .

\begin{tabular}{|c|c|c|c|c|c|c|c|c|}
\hline $\begin{array}{l}\text { Mw } \\
\left(\mathrm{kg} \mathrm{mol}^{-1}\right)\end{array}$ & $\begin{array}{l}\mathrm{Mn} \\
\left(\mathrm{kg} \mathrm{mol}^{-1}\right)\end{array}$ & Contrast & $\begin{array}{l}\text { Sensitivity } \mathrm{D}_{50} \\
\left(\mu \mathrm{C} \mathrm{cm}^{-2}\right)\end{array}$ & $\begin{array}{l}\text { Gel point } D_{0} \\
\left(\mu \mathrm{C} \mathrm{cm}^{-2}\right)\end{array}$ & $\mathrm{D}_{50} \times \mathrm{Mw}$ & $\mathrm{D}_{50} \times \mathrm{Mn}$ & $\mathrm{D}_{0} \times \mathrm{Mw}$ & $\mathrm{D}_{0} \times \mathrm{Mn}$ \\
\hline 2.5 & 2.4 & 3.6 & 3400 & 2310 & 8500 & 8160 & 5775 & 5544 \\
\hline 7.8 & 4.2 & 3.5 & 1750 & 1220 & 13650 & 7350 & 9516 & 5124 \\
\hline 13 & 12.3 & 3.1 & 600 & 370 & 7800 & 7380 & 4810 & 4551 \\
\hline
\end{tabular}

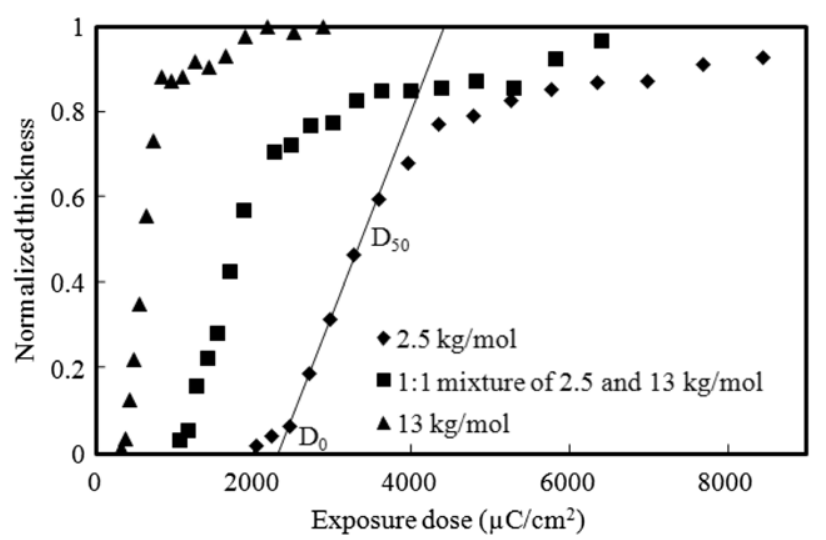

Figure 3. Contrast curves exposed at $20 \mathrm{keV}$ for polystyrene resists of 2.5 and $13 \mathrm{~kg} \mathrm{~mol}^{-1}$ and a mixture of the two with $1: 1$ weight ratio. The definition of gel point dose $D_{0}$ and sensitivity $D_{50}$ is indicated.

the high Mw polystyrenes studied above, at the cost of greatly reduced sensitivity. For the $1: 1$ weight ratio mixture of 2.5 and $13 \mathrm{~kg} \mathrm{~mol}^{-1}, \overline{\mathrm{Mw}}, \overline{\mathrm{Mn}}$ and PDI is calculated as $7.75 \mathrm{~kg} \mathrm{~mol}^{-1}$, $4.19 \mathrm{~kg} \mathrm{~mol}^{-1}$ and 1.85 , respectively. The contrast curve for the 1:1 mixture resembles a hypothetical monodisperse polystyrene resist with a Mw of 4-5 kg mol${ }^{-1}$. Since for low Mw polystyrene the resist surface after development is much smoother than for high Mw polystyrene (this is related to its higher resolution capability), the contrast curve measured by AFM is more accurate than that for high $\mathrm{Mw}$ polystyrene resists that gave rough resist surfaces after development. It is thus more meaningful to carry out a quantitative study with the low Mw resists. Table 1 lists the three resists' gel point dose $\mathrm{D}_{0}$, sensitivity $\mathrm{D}_{50}$ (dose for $50 \%$ normalized thickness), contrast, as well as the four products between $\mathrm{M}_{\mathrm{w}, \mathrm{n}}$ and $\mathrm{D}_{0,50}$. Theoretically the dose-molecular weight product should be independent of molecular weight. Apparently the products of dose and number averaged molecular weight are similar for the three resists, but those of dose and weight averaged molecular weight are very different. Moreover, $\overline{\mathrm{Mn}}$ for the mixture is closer to that of $2.5 \mathrm{~kg} \mathrm{~mol}^{-1}$ than $13 \mathrm{~kg} \mathrm{~mol}^{-1}$, so is the resist contrast. We can therefore conclude that the resist properties for polystyrene depend mainly on $\overline{\mathrm{Mn}}$ if it differs from $\overline{\mathrm{Mw}}$. It is known that for a polymer with broad molecular weight distribution, some properties such as tensile strength depend mainly on $\overline{\mathrm{Mn}}$, whereas other properties such as viscosity depend mainly on $\overline{\mathrm{Mw}}[24,25]$. Longer chains are more important for the value of $\overline{\mathrm{Mw}}$, whereas shorter ones with larger number are more important for the value of $\overline{\mathrm{Mn}}$. Therefore, here the exposure property is mainly determined by the low Mw component due to its large number.
Polystyrene resists with different $\mathrm{Mw}$ and PDI have been studied previously. Feit et al showed that for the same molecular weight of $233 \mathrm{~kg} \mathrm{~mol}^{-1}, \mathrm{D}_{80}$ (dose for $80 \%$ normalized thickness) for polystyrene with higher PDI is considerably higher than near-monodisperse polystyrene, though the difference for $\mathrm{D}_{50}$ (dose for $50 \%$ normalized thickness) is less [26]. They thus concluded that PDI is a very important parameter for a polystyrene resist. We disagree with their conclusion, and believe that a higher dose was needed in their study for the resist with larger PDI because its $\overline{\mathrm{Mn}}$ is lower for the same $\overline{\mathrm{Mw}}$. Lai et al claimed that the contrast of polystyrene resist decreases with an increase in molecular weight distribution [27]. Yet this conclusion was drawn based on the contrast curves for several polystyrene resists that differed not only in PDI but also in molecular weight. Gel formation theory also implies higher contrast for uniform $\mathrm{Mw}$ distribution (PDI = 1) than random $\mathrm{Mw}$ distribution (PDI = 2) [20]. However, it was assumed that gel fraction is equal to normalized remaining film thickness after development, which is inaccurate since gel formation is a 'bulk' process occurring throughout the film thickness whereas resist dissolution by a developer is a layer by layer surface process. Our results indicate that PDI has an insignificant effect on resist performance. One plausible explanation for this is that once two polymer chains have been cross-linked by electron beam exposure to form one larger chain, the chain length of the two original polymer molecules is no longer important, be it two molecules of equal length or not.

Lastly, we performed gel permeation chromatography (GPC) measurement on the above-mentioned general purpose polystyrene with a molecular weight of $260 \mathrm{~kg} \mathrm{~mol}^{-1}$, which showed $\overline{\mathrm{Mw}}=286 \mathrm{~kg} \mathrm{~mol}^{-1}, \overline{\mathrm{Mn}}=64 \mathrm{~kg} \mathrm{~mol}^{-1}$, and PDI $=4.5$. Due to its lower $\overline{\mathrm{Mn}}$, this polymer achieved better pattern definition than the monodisperse (PDI $=1.06$ ) $170 \mathrm{~kg} \mathrm{~mol}^{-1}$ one as seen in figure 2 . We also compared it with a monodisperse polystyrene of $62 \mathrm{~kg} \mathrm{~mol}^{-1}$ (PDI = 1.06, thus $\overline{\mathrm{Mn}}=58 \mathrm{~kg} \mathrm{~mol}^{-1}$ ) that is commercially available. As expected, and shown in figure 4 , though their $\overline{\mathrm{Mw}}$ differs by 4.6 times, the sensitivity of the two polymers is reasonably close (90 and $115 \mu \mathrm{C} \mathrm{cm}-2$, respectively). This again showed that number averaged molecular weight dominated the exposure properties of polystyrene resist.

\section{Conclusions}

Despite the fact that polystyrene's sensitivity is inversely proportional to its $\mathrm{Mw}$, no significant effect of very broad molecular weight distribution on the sensitivity, contrast and achievable resolution is observed. It is thus unnecessary 


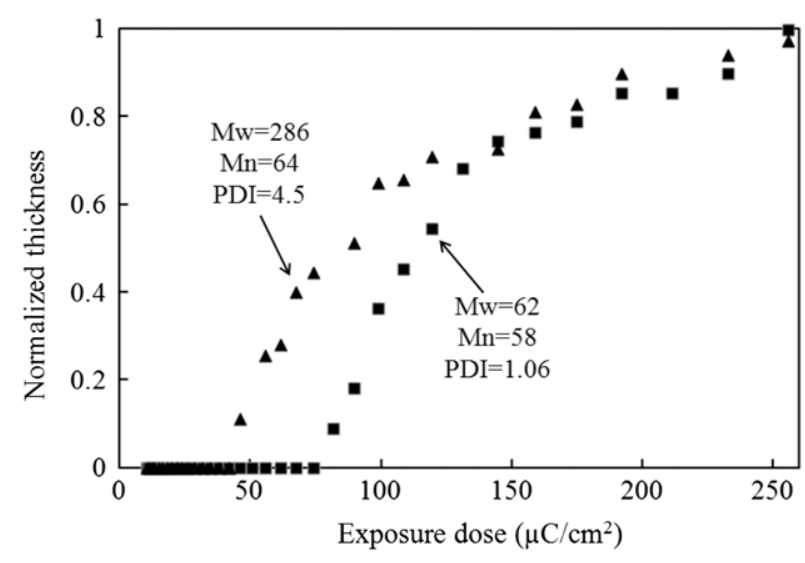

Figure 4. Contrast curves exposed at $20 \mathrm{keV}$ for monodisperse $(\mathrm{PDI}=1.06)$ and general purpose polydisperse $(\mathrm{PDI}=4.5)$ polystyrene with a similar number averaged molecular weight of $\sim 60 \mathrm{~kg} \mathrm{~mol}^{-1}$.

to use the costly monodisperse polystyrene for EBL. In our approach, we simulated a polystyrene with high PDI by mixing at 1:1 weight ratio two polystyrenes with very different molecular weights. The exposure property of the mixture resembles that of a monodisperse polystyrene with a close number averaged molecular weight $\overline{\mathrm{Mn}}$, which indicates that it is $\overline{\mathrm{Mn}}$ rather than $\overline{\mathrm{Mw}}$ (weight averaged molecular weight) that dominates the exposure properties of polystyrene resist. We also studied a general purpose polystyrene with a high polydispersity of 4.5 , and found that its properties is comparable to those of monodisperse polystyrene having similar number averaged molecular weight. Therefore, one can use the low-cost general purpose polystyrene for EBL; and one doesn't need to have a large number of polystyrene resists with different molecular weights for different applications using EBL, as any given molecular weight can be simulated by a mixture of two polystyrene samples having different molecular weights.

\section{References}

[1] Hajiaboli A, Cui B, Kahrizi M and Truong V V 2009 Phys. Status Solidi a 206976

[2] Bilenberg B, Schøler M, Shi P, Schmidt M S, Bøggild P, Fink M, Schuster C, Reuther F, Gruetzner C and Kristensen A 2006 J. Vac. Sci. Technol. B 241776

[3] Clark N, Vanderslice A, Grove R and Krchnavek R R 2006 J. Vac. Sci. Technol. B 243073

[4] Con C, Abbas A S and Cui B Presented at EIPBN May 2012

[5] Zhang J and Cui B Presented at EIPBN May 2012

[6] Ma S, Con C, Yavuz M and Cui B 2011 Nanoscale Res. Lett. 6446

[7] Con C, Dey R, Ferguson M, Zhang J, Mansour R, Yavuz M and Cui B 2012 Microelectron. Eng. 98254

[8] Liping L, Yajiang H and Qi Y 2011 J. Macromol. Sci. B $\mathbf{5 0} 2140$

[9] Chen C, Hsieh T and Ju M 2009 J. Alloys Compounds 480658

[10] Itaya K, Shibayama K and Fujimoto T 1982 J. Electrochem. Soc. 129663

[11] Manako S, Fujiga J, Ochiai Y, Nomura E and Matsui S 1997 Japan. J. Appl. Phys. 367773

[12] Manako S, Fujiga J, Ochiai Y, Nomura E and Matsui S 1997 Japan. J. Appl. Phys. 36 L 724

[13] Ochiai Y, Manako S, Fujita J and Nomura E 1999 J. Vac. Sci. Technol. B 17933

[14] Austin M, Zhang W, Ge H, Wasserman D, Lyon S and Chou S Y 2005 Nanotechnology 161058

[15] Whipps P W 1979 Microcirc. Eng. 118

[16] Jagt J C and Whipps P W 1980 Philips Tech. Rev. 39346

[17] Ku H Y and Scala L C 1969 J. Electrochem. Soc.: Solid State Sci. 116980

[18] Yan M, Choi S, Subramanian K R V and Adesida I 2008 J. Vac. Sci. Technol. B 262306

[19] Khoury M and Ferry D K 1996 J. Vac. Sci. Technol. B 1475

[20] Atoda N and Kawakatsu H 1976 J. Electrochem. Soc.: Solid State Sci. Technol. 1231519

[21] Sugita K and Ueno N 1992 Prog. Polym. Sci. 17319

[22] Sheiko S S, Gauthier M and Möller M 1997 Macromolecules 302343

[23] Shokouhi B, Zhang J and Cui B 2011 Micro \& Nano Lett. 6992

[24] McCormick H W, Brower F M and Kin L J 1959 Polym. Sci. 3987

[25] Merz E H, Nielson L E and Buchdahl R 1951 Indust. Eng. Chem. $\mathbf{4 3} 1396$

[26] Feit E and Stillwagon L 1980 Polym. Eng. Sci. 201058

[27] Lai J H and Shepherd L T 1979 J. Electrochem. Soc. 126696 